Gut, 1989, 30, 561-564

Leading article

\title{
Aetiology of cancer of the oesophagus: geographical studies in the footsteps of Marco Polo and beyond
}

Three areas in the world have a high prevalence of cancer of the oesophagus. Two lie at the extremes of the old silk routes pioneered by Marco Polo around the shores of the Caspian Sea in northern Iran and in the Henan and Shanxi provinces of China. The third area, with the highest prevalence, is the Homeland state of Transkei in South Africa. Cancer of the oesophagus here is 14 times more common than hepatoma - the next most common malignant tumour - and in southern districts accounts for $20 \%$ of all adult deaths. ${ }^{1}$

Possible aetiological factors include a similar diet; in particular, a diet rich in cereal but poor in fresh fruit and vegetables. In the Chinese regions a pot of millet gruel is often the sole food while home-made bread is the staple diet around the Caspian littoral. In Transkei, maize is grown to the virtual exclusion of all else irrespective of the suitability of the soil or climate. These diets are deficient in riboflavin and vitamins $\mathrm{A}$ and $\mathrm{C}$. The three areas also share similar poor quality soil, deficient in trace elements, especially zinc and molybdenum. Zinc deficiency has been implicated in the development of oesophageal cancer under experimental conditions ${ }^{2}$ whilst molybdenum is a cofactor for the enzyme nitrate reductase so that deficiency allows nitrosamines to accumulate in plants.

Each of the three areas have regional peculiarities which are probably of aetiological significance. Alcohol and tobacco, major risk factors in the West, play little or no role in Islamic Iran. The use of opium, however, correlates closely with local variations in oesophageal cancer incidence. Tests for urinary morphine metabolites indicate that the majority of the adult population are opium addicts in affected areas. The tarry residues from opium pipes are frequently eaten mimicking similar practices seen in the Transkei.

The disease in China is particularly common around the foothills of the Taihung mountain range in the north east. The ancients recognised the sinister portent of dysphagia where a 'Throat-God Temple' existed which sadly was destroyed by war in 1927 . Nitrosamines and their precursors have been identified in drinking water and food samples. ${ }^{4}$ In Linxian, for example dry wells are used to collect and store rain water. This water is contaminated with human and animal waste but even so is taken home for storage in large ceramic jars. The nitrite content is considerably higher than the levels found in well water in areas of low incidence. Food is often contaminated with fungi and several species can reduce nitrates to nitrites. Both mouldy food 
and pickled vegetables (a popular food in the high incidence areas) induce epithelial dysplasia in the oesophagus. Both man and chickens in Linxian have a high prevalence of oesophageal cancer. Millet seed containing silica has also been implicated because silica particles have been identified on electron microscopy of biopsies from oesophageal cancer.

Two million people in the Transkei belong to the Xhosa tribe. This is a static, non-migrant population who are dependent upon subsistence farming. While the incidence of oesophageal cancer in most places is low, the unfortunate Xhosa have a very high incidence. Doll reported an annual figure of 357/100000 men aged 35-64, a figure exceeded in his study only by Kazakhstan in the USSR. ${ }^{5}$ This high incidence seems to be a recent phenomenon, Burrell in $1957 .{ }^{\circ}$ Several studies have since confirmed an increasing incidence which may be in part attributed to a greater awareness of diagnosis. The low incidence of oesophageal cancer recorded at hospitals such as the All Saints' Mission in the 1950's has been reported from other hospitals in the Transkei ${ }^{7}$ but the disease is now endemic in Transkei.

The Xhosa are an important population to study because they have well defined, unchanging customs and habits. The people live and die in the same village, obtaining their sustenance from the local neighbourhood. There is little population movement, especially among the women. The population is remote from Western influences but even remote areas have been brought closer to medical attention by the increased willingness of the medical services to work in these rural areas so that there is increased reliance of the Xhosa on western medicine. Witch doctors, however, remain an integral part of the community. Xhosa superstition is preeminent and the people will accept medical techniques only if they do not conflict with their own beliefs. Barium swallow examination is regarded as treatment. The Xhosa consider oesophageal cancer is the result of introducing a black spider into their beer by sorcery which reaches the oesophagus and slowly increases in size. Barium, being white, is good medicine against the black spider, which is further damaged by the 'lightning' emitted by the $x$-ray imaging.

Maize is fermented to make Xhosa beer which contains a high concentration of nitrosamines. The containers used for brewing and storing the beer are often also used to store other liquids such as petroleum and asphalt. Substances such as liquid metal polish may be added to the brew before drinking. ${ }^{\circ}$ The maize beer drunk by the Xhosa is thus a potent brew. Sorghum has, in the past, been used for brewing beer in Transkei as well as in the other parts of Africa. ${ }^{9}$ Despite suggestions to the contrary, "1 it has been replaced for several decades by maize, which produces a light coloured beer albeit with an unpleasant taste for the unaccustomed Western palate. Sorghum is the most widely consumed cereal in Rwanda, where it is used to prepare the traditional beer consumed by nearly all Rwandans." Oesophageal cancer is uncommon in Rwanda.

The Xhosa of both sexes are inveterate smokers from adolescence although the practice is less common among the educated Christian Xhosa. Long stemmed pipes are used to smoke tobacco that is grown, cut, and dried beside the mud huts. The tobacco is highly mutagenic when evaluated by the Ames' test. ${ }^{12}$ The pipe stem juice, injonga, is chewed and swallowed while still hot. Injonga has very high levels of nitrosamines. ${ }^{13}$ The long stemmed pipes are made of the heartwood of Acacia caffra. Two varieties of tobacco are grown - irhamenti, which is a very strong tobacco 
with small or dwarf yellow flowers, and icuba, a tall pink flowering milder tobacco. The leaves of both are dried inside the mud huts. To give extra flavour, marijuana ('dacca') growing wild, is often mixed with tobacco. Throughout the world, smoking and oesophageal cancer appear to be causally related. The association in Transkei is accentuated by the use of tobacco which is mutagenic and the habit of swallowing hot pipe stem juice.

The nutritional status of the Xhosa is poor. Malnutrition is a common cause of death in infancy and tuberculosis is rife. The soil is of variable quality. Zinc and molybdenum deficiences have been identified in the north by agricultural surveys. Molybdenum deficiency is obvious in northern areas because of the 'withered end' appearance of the maize plants. In molybdenum deficiency, death of the plant leaf progresses from the tip of the leaf towards the base forming a clearly demarcated line without the usual intervening yellow-green area. The leaves are affected from the base of the plant upwards. Molybdenum deficiency increases the susceptibility of maize to a variety of fungal infections and infected maize is frequently used, out of necessity, to brew beer.

Studies in China ${ }^{414}$ have shown an inverse correlation between death from oesophageal cancer and the water and food levels of zinc and molybdenum. Low molybdenum content in soil allows the accumulation of nitrosamines in plants. Zinc deficiency may act synergistically in promoting nitrosamine induced oesophageal cancer. ${ }^{2}$ Studies by the author have however, failed to lend any support to the role of zinc and molybdenum in oesophageal carcinogenesis at least in Transkei. ${ }^{15}$

A large irrigation system has recently been built in the Engcobo region of Transkei and the Xhosa have been supplied with zinc phosphate and ammonium molybdate fertiliser. Whilst these measures may improve the poor nutritional status of these people, efforts directed at modifying their smoking and drinking habits should, with time, reduce the appalling incidence of oesophageal cancer. At present in these areas prevention offers the only hope.

P M SAGAR

University Department of Surgery,

The General Infirmary at Leeds,

Leeds,

LS1 3EX

\section{References}

1 Warwick GP. Some aspects of the epidemiology and aetiology of oesophageal cancer with particular emphasis on the Transkei, South Africa. Adv Cancer Res 1973; 17: 81-229.

2 Fong LYY, Sivak A, Newberne PM. Zinc deficiency in methylbenzylnitrosamine induced oesophageal cancer in rats. $J$ Natl Cancer Inst. 1978; 61: 145-50.

3 Joint Iran - International Agency for Research on Cancer Study Group. Oesophageal cancer studies in the Caspian Littoral of Iran: Results of Population Studies - a prodome. J Natl Cancer Inst 1977; 59: 1127-38.

4 Yang CS. Oesophageal cancer in China. Cancer Res 1980; 40: 2633-44.

5 Doll R. The geographical distribution of cancer. Br J Cancer 1969; 23: 1-8.

6 Burrell RJW. Oesophageal cancer in the Bantu. S Afr Med J 1957; 31: 401-9.

7 Rose EF. Interim report on the survey of cancer of the oesophagus in the Transkei. $S A f r$ Med J 1965; 39: 1098-101.

8 Burrell RJW, Roach WA, Shadwell A. Oesophageal cancer in the Bantu of the Transkei associated with mineral deficiency in garden plants. J Natl Cancer Inst 1966; 36: 201-14.

9 Rose EF. Nutrition and oesophageal cancer. Lancet 1987; i: 1143. 
10 Oterdoom HJ. Preventing oesophageal cancer. Lancet 1987; i: 745.

11 Manchande JP, Mets T, Klion A. Aetiology of oesophageal cancer. Lancet 1987; i: 1499.

12 Wehner FC, van Rensburg SG, Thiel PG. Mutagenicity of marijuana and smoke condensates in Salmonella/microsome assay. Mutat Res 1980; 77: 135-42.

13 Rose EF. A review of the factors associated with cancer of the oesophagus in Transkei. Prog Clin Biol Res. 1981; 53: 67-75.

14 Cancer Institute (Hospital) of the Chinese Academy of Medical Sciences. Annual Report. Beijing: China, 1978.

15 Sagar PM, Ellwood RW. Risk factors in ocsophagcal cancer. Lancet 1987; i: 508. 